\title{
Global Management Practices and Strategies in the IT Driven Society
}

\author{
Cristina MORĂRESCU1 \\ Simona Cătălina STEFAN² \\ Stefan Cătălin $P O P A^{3}$ \\ Cătălina Florentina $A L B U^{4}$
}

\begin{abstract}
The main objectives of the paper are: to identify and analyze the main ways in which global management practices and strategies can be adapted to survive in the context of the IT driven society, to determine which are the best ways in which managers can deal with the challenges of running global teams, to determine new guidelines, in order to accommodate the common shared digital workspace such created, and to change the approach in which the managerial functions and the management process itself is being regarded in, considering the continuous changes of the digital environment, as the current global workspace evolves. In terms of significant results and conclusions, may be mentioned the ones regarding the necessity of shaping a set of new management practices and strategies capable of validating the real requirements of the new social and economic background in which organizations exist in, and the fact that the traditional way in which the management process unfolds is no longer enough. Also, the paper comprises a set of basic guidelines to be followed in terms of establishing current management trends and practices in the IT driven globalized society, which today's practitioners can use when making their own rules of the game, according to the specific context. Given the dynamic of the environment, further research should be considered and conducted in order to better comprehend the way in which managers need to act so that their companies fully benefit from the information technology opportunities.
\end{abstract}

KEYWORDS: global management, management process, management practice, information technology, innovation.

JEL CLASSIFICATION: F61, L86, M16, O32, Q55

\section{INTRODUCTION}

Worldwide a process of globalization has continuously developed - imposed by the credible desire of the powerful states to integrate as many economies (in particular those of underdeveloped countries) - which gradually included almost all fields of activity. This has caused problems for many companies to adapt to their external environmental conditions. As such, management, has had to deal with more and more challenges, as a result of the evergrowing common global environment created.

The way to integrate as many companies into the global economy was possible due to measures such as the free movement of labor in many developed and even in underdeveloped countries, the liberalization of financial-banking markets, financial capital, etc. The

\footnotetext{
${ }^{1}$ The Bucharest University of Economic Studies, Romania, crysthina2003@yahoo.com, corresponding author

2 The Bucharest University of Economic Studies, Romania, simonacatalina_2006@yahoo.com

${ }^{3}$ The Bucharest University of Economic Studies, Romania, popacatalinstefan@yahoo.com

${ }^{4}$ The Bucharest University of Economic Studies, Romania, albucatalinaflorentina@yahoo.com
} 
consequences of these measures were not long awaited, as a fierce competition at the economic and commercial level is constantly being intensified. Highly skilled workforce moving / migrating to countries that strongly support research and innovation have created new technologies capable of revolutionizing many areas of activity.

A leading field of activity - which dominates the present industry - is that of information technology, communications and that of audiovisual business. Global competition has also impacted the competitiveness of national economies. And finally, the rush to have products/services capable of winning over as many markets as possible has led many companies to not always act in the best interest of the environment, even if the talk of the town is somewhat driven towards corporate social responsibility and issues regarding sustainability, durability and the future of the next generations.

The economic characteristic of globalization is the interpenetration of national economies that is reflected in increased commercial trades, investments and foreign capital. The negative consequence of these interrelations can be a global economic and financial crisis (produced by the development of in-country imbalances, which breaks/destabilizes the international linkage). Even with this risk, global businesses are functioning throughout the worldwide economy, relying on market expansion.

The main objectives of the paper are: to identify and analyze the main ways in which global management practices and strategies can be adapted to survive in the context of the IT driven society, to determine which are the best ways in which managers can deal with the challenges of running global teams, to determine new guidelines, in order to accommodate the common shared digital workspace such created, and to change the approach in which the managerial functions and the management process itself is being regarded in, considering the continuous changes of the digital environment, as the current global workspace evolves.

As global economic exchanges are increasingly developing, it has been found that such transactions can be facilitated by investing creative and innovative human capital in high-tech information and communication fields. The preoccupation of specialists in super high-tech IT field has become more than evident in the last decade of the century. The interconnected global economy creates transnational corporations that potentiate a system of interdependent markets; the latter (system) would not be possible without digitization. Beginning with computer systems capable of producing through robotics, high performance, competitive, diversified and tailor-made products adapted to meet the needs of the marketplace, and continuing with their fast and efficient promotion, distribution and delivery. Also, with hightech information technology, production, marketing and management costs are significantly reduced. Coordinating the activities of global organizations, on one hand, is relieved through the use of telecommunications and top-level information systems which create a new way of doing things, on the other hand, management of such organizations is the on left dealing with figuring out which is the best way to do business in the new digital environment. As planning of business/production activities is done through direct/online communications means, acting accordingly depends on understanding the momentary changes of the everchanging context. As such, managing global businesses and establishing strategies resumes more to "here and now", paradoxically even when physical distances are great, and time zones are different.

Currently, as a direct consequence of the IT driven society, many companies have expanded their marketing, supply and production activities in many regions that they considered opportune for them precisely because of the instant transmission of information, which is so necessary for expansion. 
The IT era has brought on the new, and the fact that, if in the beginning firms were helped to control the markets, now the companies that became giants can, through advanced information technologies, consolidate this control at a scale that they have not been able to achieve without IT, dominating the world economy. The success of many gigantic economic, financial companies is largely due to their efforts to support research, development and technological innovation. Valuing the knowledge-inducing, especially innovative human potential, has empowered organizations, enabling them to maintain progress. Expenditures of companies with these knowledge-rich human resources are amortized by the increased productive efficiency of team members and managers.

We have seen that without the stimulation of research and innovation, it is not possible to obtain development that in the end reflects welfare. Facilitating communication development, through IT, creates interconnected networks of various dimensions, linked at micro and macroeconomic levels. A well-established IT based business network can sustain a management process able to better prevent, anticipate, detect and deal with all-level/all-type challenges and malfunctions. Today's society and economy are more than ever before, firstly digital: through IT, especially with the help of the Internet, social networking, social media, companies find it easy to improve their efficiency in the economic and social environment but seem to be struggling when it comes to managing certain situation created by the globalized context. Most successful businesses carry out their extensive activities in various areas through the use of IT, they are based on advanced data processing technologies, and ease their work by reducing bureaucracy, by understanding that management needs to increase the flexibility of its strategies and assume a more active role in the adaptation of the managerial process.

Benefits of the IT driven society much outweigh the challenges, the effectiveness of a company's activities being evident by noticing things such as: creating a proximity to the potential buyer, a more detailed knowledge base of the competitive demand and supply, travel cost reduction for promotion, know-how transfer, overall total time won, and so on. But maybe, we should ask ourselves if this time saved could be put to better use by the management of these organizations in order to further take advantage of the opportunities and to create practices and strategies to intensify the overall performance.

Lately, information gained a lot of importance, being considered by many specialists and practitioners as a basic resource of the successful business. It can be said that it has become a commodity - which creates a huge advantage in this global competitive environment. This mainly allows human resources of organizations that are based on IT systems communication to improve their potential due to a faster accumulation of vital information and a timelier efficient activity. However, the manager is the one responsible with the coordination of members of such teams created in the digital workspace and he needs to facilitate communication, monitor and control the relationships formed more effectively, better forecasting and predicting obstacles.

Also, the new way of working and doing business, remotely/online creates new opportunities, relieves certain efforts for employees/managers and facilitates cost reduction for the company. The possibilities on the global labor market for companies to find highly qualified personnel increase and lead to a better match in terms of employer-employee, which in turn creates a better fit and sustains the achievement of economic performance. Another advantage for a global organization refers to location and the thinning of location boundaries, which allows it to quickly find out deficiencies in a remote region, act accordingly through digital means, better understand and interact with potential partners or geographically distant competitors, and so on. However, these virtual dimensions of business can also pose risks and result in 
challenges, generating a shift in trends in terms of applied management practices, as certain things cannot still be done the same way as in the past, which if not dealt with properly can have a major influence with significant consequences on the economic side of a business.

The relationship between organizations and the global environment is more powerful than ever, the necessity to investigate and shape certain guidelines to be followed by the managers of these entities being indisputably essential. In order to fully take advantage of the global economic and social growth potential created by the super high-tech business environment new strategies should be formed in order to develop a sustainable managerial process.

\section{LITERATURE REVIEW}

"The main beneficiaries of globalization are undoubtedly the employees of the transnational companies and those symbolic analyst professionals who serve these companies - lawyers, researchers, consultants, IT experts, and so on...the changes in IT have been one of the major enabling factors behind globalization" (Singh \& Verma, 2010).

According to Hill (2009) globalization can be objectively measured at corporate level trough their strategy and planning process, corporate governance and corporate responsibility, research and development activities, market orientation, organizational and human resources management, operations and level of technology employed, while information technology may be considered as major facilitators of business globalization.

Many technological breakthroughs connect the world. Digital electronics, miniaturization, telecommunications, computers, robotics, artificial intelligence, genetic engineering, lowflying satellites, and lasers are only a few among many information technologies that shape our lives. But other information-based industries such as medicine, education, and engineering have also witnessed breakthroughs that are also dependent on knowledge, computers, and networks. Examples from any one could demonstrate that connectivity stimulated by technological change spills over into other global environments such as global culture, politics, and economics to create business opportunities and challenges. Development of and convergence among computer, the Internet and telephony illustrates how these three contribute to an interconnected world (Parker, 2005).

In recent years, globalization forces have determined changes of behaviors and policies, both at corporates and states level, thus being considered as a major environmental factor in shaping managerial practice as well as managerial theory (Rao, 2001). According to David C. Thomas (2008), the practice of management is a dynamic process and, as globalization increases the amount of intercultural contact in organizational settings, the inadequacy of our present understanding of management to explain and predict behavior in these settings becomes more apparent (Thomas, 2008).

As the digital technology era arises as an undeniable worldwide reality, managers are beginning to understand that new practices and strategies should be more thought out, improved and established as to take into consideration all the opportunities and challenges that global cross-cultural organizations and projects imply. As the boundaries of communication continue to constantly shift, companies must figure out what are the new guidelines, in order to accommodate the common shared digital workspace such created.

For some organizations, the digitalization of their business was, and still is, their major challenge forms a change management viewpoint (Ribeiro, 2011). As such, digital's the word 
and everyone is trying to keep up. However, the information society should consider its multiple implications at individual, organizational and national levels. Computers are empowering tools, which grant unprecedent access to global communications and information, but they also may be considered as a control tool for those who control the information (Feather, 2004).

"Complexity of contemporary management practice is expressed in a necessity to improve management processes that refer to various spheres of enterprise operation. One of such spheres comprises of projects management, which is currently becoming a dominating dimension of management practice" (Dolata \& Standa, 2014).

According to Rabi S. Bhagat, Harry Charalambos Triandis, and Annette S. McDevitt, authors of the book - "Managing Global Organizations: A cultural Perspective" (2012), cultural differences affect, among others, the kinds of management styles that will be effective, the way innovations are likely to occur and to become accepted, and many other aspects of organizational behavior (Bhagat, Triandis, \& McDevitt, 2012).

"Future managers should be prepared to deal with different cultures, variable functions, other companies and industries, and varying backgrounds. The job of future managers, as well as the risks involved, will be particularly challenging" (Alkhafaji, 1995).

In the global business environment, the global teams are a fact of life for both employees and managers, becoming the basic organizational structure for many multinational companies. They are groups of people working and interacting virtually across time and organizational, cultural and geographical boundaries, lead to their mutual goals. "Since the 1990s, the growth in global teams has increased exponentially as companies have invested resources in people and in organizational and technological infrastructure to connect technical expertise and local knowledge for the purpose of achieving shared global business objectives" (Lane, Maznevski, Mendenhall, \& McNett, 2004).

"World leaders understand that global business can be complex, and there are always studying it from multiple perspectives [...] the talented global leader oversees an organizational system that seeks to enable each employee to reach his or her potential" (Moran, Harris, \& Moran, 2011).

"Clearly global communications and information technology has shaped the rise of multinational enterprises and the strategies they adopt" (Tansey, Darnton, \& Waterbridge, 2003). Information technology is now part of the emerging postindustrial style of management, involving how they trade as understanding accounting, business law and human resource management. Therefore, their personal and enterprise success are increasingly dependent on managers understanding of how to acquire, manage and dispose of information technology and related services (Cortada, 2009).

\section{MANAGEMENT PRACTICES AND STRATEGIES IN THE IT DRIVEN SOCIETY}

\subsection{Research Methodology}

Starting from the main objectives of the paper, which are: to identify and analyze the main ways in which global management practices and strategies can be adapted to survive in the context of the IT driven society, to determine which are the best ways in which managers can deal with the challenges of running global teams, to determine new guidelines, in order to accommodate the common shared digital workspace such created, and to change the approach 
in which the managerial functions and the management process itself is being regarded in, considering the continuous changes of the digital environment, as the current global workspace evolves; a research methodology was constructed to support the current unfolded process.

The undertaken theoretical research expresses the purpose of developing certain conceptual aspects regarding global management practices and strategies specific to the IT driven contemporary society and to bring own contributions to the further evolution of the management field by providing a basis for future research. The research tools utilized refer to the review and study of literature. After the establishment of pursued key concepts, relevant studies in the field were identified and analyzed in order to permit a selection and discussion of the most appropriate theoretical material needed to paint an image regarding the present subject proposed for development. Information collected includes relevant theoretical and contextual literature studies and offer a significant background needed to introduce the topic chosen. The literature review section includes a brief and clear presentation of previous theories and research closely related to the research theme and was used to generate an individual approach underlined in the next two sub-sections.

In terms of expected results of the research, we mention that data and information collected from the literature review were used, as a starting point, to create an individual contribution made by the authors, comprised of a set of new guidelines in terms of the global management process and practices, on the one hand, and of management strategies according to the requirements of the digital environment, on the other hand, which are presented below. The outlined guidelines were based on the identification and adaptation of current management practices and strategies and sustain the opportunity of developing a starting point for managers, specialists and other researchers in the journey of navigating through the challenges of the IT driven society.

\subsection{The New Global Management Process and Practices}

Understanding the global business environment means understanding how to cope with the challenges and rapid changes that can engender opportunities for the new economic agents. Today's business environment, more than ever, is faced with challenges and contradictions generated by the domination of globalization and digitization. For the management there will always be question marks created by these challenges regarding the strategies chosen for the future of the organization, in order to increase the sustainability of the business. Now, besides appropriate managerial strategies, digital communication practices are created, which have the potential of obtaining and maintaining not only a competitive advantage for the company, but also of conturing a team of highly qualified and satisfied employees, capable of further developing and creating innovative products/services. That is why, due to the digital age, management is helped to support entrepreneurship and the business environment, providing opportunities for those interested in engaging in the creation and development of new business models that are based on innovative ideas or alternative strategies, different from those traditionally known. In this case, management must adopt innovative strategies that can encourage not only the potential of the human resource, but also to propel the business into a pioneering one, which not only satisfies the current needs of the consumer but also predicts the new ones, and dynamically responds to them in an efficient manner.

Managerial functions start to be viewed as differently given that the managerial process itself, along with its phases is thought out, developed and applied in a global digital community, in 
which collaboration, alongside the participatory nature supports a new type of unlimited interaction supported by the disposal of physical borders. And even though the core of the management process remains unchanged, as such, "irrespective of the field in which it is exercised, of the hierarchical level at which it is carried out can be achieved through the exercise of the following functions: provision, organization, coordination, training and control-regulation" (Burduș \& Popa, 2013), it is essential that we regard these functions as accomodating to the continuous changes of the digital environment. For example, let us think of the following question: what does it imply to a coordinate a team of subordinates from different countries, communicating without the use of face-to-face interactions, and taking into consideration differences in terms of language, time zones, culture, social and political aspects and so on? The truth is that this causes real whirlpool of situations, with which managers must deal with it and figure it, whilst not overlooking the overall strategy of a company; and the same can be asked about all the other four management functions and implicitly the management process. The raised questions create a dynamic which needs further research and altogether the necessity of shaping a set of new management practices and strategies capable of validating the real requirements of the new social and economic background in which organizations exist in. Therefore, we have comprised a set of basic guidelines to be followed in terms of establishing current management trends and practices in the IT driven globalized society, which today's practitioners can use when making their own rules of the game, according to the specific context.

The main objective of such a top management system is to provide a vision of both change and, above all, adaptation to the socio-economic environment in which it is defined. This type of successful management must: demonstrate expertise on the characteristics of the industry; clearly define the place and the role of the business - within the realistic limits and objectives; outline a plan/strategy that will lead to the achievement of the established objectives; to take into account traditional practices, but to use systems, methods and techniques adapted to the digital age; take part in transforming an organization by building projects able to face entrepreneurial challenges determined by the characteristics of the IT driven society.

But change cannot be achieved if past is not fully understood. Therefore, only by knowing important methodologies of managerial practices and strategies - regarding different specific aspects, of which we mention the following: phases of the management process; evolution and interdependence of management functions; main ways of business development; understanding and anticipating new customers' needs; launching/managing a business or innovation; entrepreneurship strategies; the ability to take into account the social responsibility issues of the business; - can new management attempts and approaches be made easier in this digital age.

Understanding the growing importance of social networks in product placement, commercial marketing, in communicating with loyal/new/potential clients, in easy and convenient electronic commerce, as well as in managing different business activities through the smart us of information technology and communications, and last but not least, in an intercorrelation of the markets, or of various concerned business environments.

The emerging digital revolution focuses on a predominantly IT driven society that also has implications on the business environments that are conducive to an increasingly viable, innovative economy. But the pitfalls of this context are not few, and they also challenge business managers through the speed of accessing confidential data, through the ever-growing capacity of developing innovative ideas, through different ways of accessing artificial 
intelligence, through the risks arising from the development of free digitized societies that can lead to abuses in different environments, which in some situations can even go up to the violation of certain consumer/society rights.

A business managed in the digital age can mean not only development but also greater and easier visibility on an expanded level, with social networks, online platforms, virtual communities, and search engines propelling innovative startups to success. More and more entrepreneurs create useful connections and receive understanding, guidance and support from them which help in directing their focus on the evolution of their businesses.

This digital revolution sometimes dramatically influences the business environment, mainly in terms of data management, which leads to a much higher visibility / predictability / control over the traditional may of doing things. Internet use also configure the business environment and, implicitly, management. For example, online marketing creates new consumer experiences that cause somewhat of an addiction to such technologies; companies are also subjected to cyber security risks that may have adverse consequences for themselves and for the customer. Management in the online environment also involves costs / investments that foresee the new risks of digitization.

Global management must consider the close relationship between business and its connectivity with the "outside" world. So prioritizing investments in digital infrastructure is the key to effective management of the future. An appropriate managerial approach in the context of rapid technological evolution can make a difference, but also stimulating an innovative environment can increase the chances of success in the business. The impact of digitization is enormous, influencing both employers and employees - especially from the point of view of changing jobs - tailored to basic training, and another aspect that must not be neglected at all refers to information security.

Nowadays, the step taken from creation to creativity to innovation that is to take that creative product/service and transform it into one that can be used by more potential customers is facilitated by digital connectivity. The latter keeps us anchored more efficiently to the needs of our customers. It is a faster and more efficient way to find out what the customer / potential client wants, through digital interaction, we understand more quickly what their needs are and find ways to satisfy them. A remarkable example is the creation of smartphones - a product that can replace a computer, a camera, a phonebook, an organizer, and so on, innovative and well-loved product, without which we could not imagine our lives now. We can see that today a strategy of innovation must be the basis for effective management. The manager must have the ability to anticipate the next product or requirement of his or her client, he or she must focus on their needs, finding solutions to solve the problems they have not yet encountered.

Current opportunities and challenges for management are topical in the context in which the digital revolution has changed and continues to change human resources activities. The alert pace is increasingly visible in all areas of activity of a company, especially in terms of economic performance, due to the fact that high volume valuable information is transmitted quickly and often in real time globally, therefore the ability of a manager to rethink the strategy on the go and to adapt it to the changes that appear can help the evolution of the business.

Means through which managerial approaches can evolve in the context of the IT driven society should include: stimulating employees with high professional performance; maintaining employee involvement in sustaining business activity; stimulating those 
managerial skills that help the organization cope with change requirements; creating values and behaviors that will benefit business competitiveness; creating and especially maintaining a high level of learning of the new technology.

The big challenge lies in the responsibility of leaders and managers, who must inspire confidence, be able to cluster and inspire the employees who have and use the skills appropriate to this virtual new workspace created. The key is innovation for the future through an appropriate strategic process that values and stimulates innovative people. In this environment, the ability to quickly decide and to assume it can make the difference between success and bankruptcy. Nowadays, the leader is associated with everything digital, his "splitsecond" decisions depending on real-time information, given the fact that yesterday's news tends to be exactly that, and changes in management need to consider the way that future generations will be involved in the process. Managers need to have a clear vision and be able to establish well-outlined objectives, which doesn't differ from the traditional ways of roles and functions, but also be able to attract and keep motivated innovative high-potential human resources, capable of not only sustaining their strategy, but also further develop it.

As a preliminary conclusion, management should not be a collection of tips or recipes that you have to exactly use, on the contrary, the art of successful management lies in the understanding of free license to choose what exactly works for you in terms of how to stay creative and to stimulate and maintain an increased innovation level, which in turn develops and stimulates the company, making it capable of evolving and coping with the dynamics of the modern society. There is no "one size fits all" solution, global managers need to constantly update their knowledge levels, since that is the only way in which they can keep up with the trends and figure out which are the best management practices and strategies. As Hamel (2007) pointed out, the modern management brought us undisputed benefits and accomplishments, but also unexpected perspectives and issues, which unbalance the existing trade-offs, demanding fresh approaches and bold thinking. "And when we look forward, we are confronted by a slew of new problems - predicaments and dilemmas that lay bare the limits of our well-worn management systems and processes" (Hamel, 2007).

\subsection{Identification and Adaptation of Management Strategies according to the Requirements of the Digital Environment}

In this global and computerized world, we need new ways of thinking about management strategies, needed to guide companies in coping with challenges and staying viable in the big scheme of things. The business environment also based on rapid changes that are largely driven by innovation, especially in super-technological IT domains, means that for current management to be competitive it must adopt strategies that deal with the new work environment.

Classic and well-known advantages of using high-tech digital technologies that boost company performance trickle down and significantly influence the management process itself through: access to global studies that generates a better substantiation of strategies, more rapid analysis and testing methods, continuous control and evaluation, new means of coordination and communication, new motivation techniques generated by evolved needs of the human resources, new organizational structures, and so on.

Today more than ever, it would not be easy for the global economy to exist without an evolving digital economy. Encouraging innovation, stimulating access to new technologies that are applicable in different areas can be a step forward in supporting competitive business 
environments. At the management level, it requires an ability to feel, anticipate, "see" or better to predict the global environment of the organization by constantly controlling and assessing the activity. The manager must also not neglect that organizational flexibility that can boost creativity - innovation and, implicitly, the company's success.

At the basis of a successful global management strategy in the current society there must be: a managerial capacity to really assess the external environment by anticipating potential events - especially the anticipation of some seemingly unpredictable ones; a more comprehensive vision so as to determine a longer-term plan that can even influence the environment to better achieve the proposed objectives; from those predefined objectives, a plan of activity is made, followed by the setting of short-term objectives adapted to the organizational culture and its structure, continually assessing the internal activity environment. This internal evaluation is based on: the development of strategic options, selecting the successful ones whilst still experimenting with other future perspectives. Besides these processes, the re-evaluation of the strategy according to the evolution of the external environment should not be neglected. However, the idea of sustainability of the managerial methods used up to now is in question, caused by the increased ability of companies to constantly personalize their entire activity structure, employees, products, production, strategies that can be updated at all times.

Management needs to consider continuous collaboration at all levels of the organization, but also with the outside environment. The main management strategy emphasizes continuity, simultaneity and feedback from and towards its work and competitive environment, with experimentation and risk increasingly being attempted by opportunistic firms that promote innovative ideas to reach the hoped-for success rate.

Managerial strategies must also consider the degree of skill, competence, motivation of its staff, of adaptation to changes in the legislative market, the degree of involvement of all those involved in the process. All managers who understand the changes that have taken place in the digital age can create much clearer strategies in the pursuit of success. The rapid evolution of information and communication technologies rewrites the rules of managerial success, and only by capitalizing on the huge contribution of digital information can we find the key to managerial strategy in the future. Business confidence and partnership has so far been reconfigured through likes and shares, which also determines a transformation at organizational level and thus in the way the management process is being realized. And since traditional employees are being replaced by consultants, freelancers, or even robots, the workforce must be in line with the new challenges, and the only way this can happen is if the change starts to take place from the management point of view. Mainly, managerial strategy should focus on increased employee involvement and skill adaptation, and not just on benefits of easier access to information or high-tech communication, but rather to exploit this technological opportunity in redefining the business through management practices focused on the constantly evolving needs of all the types of company stakeholders; this basically requires an overall business model transformation.

In the digital age, a customer focus is essential, especially through social networking. This interaction is possible through an appropriate strategic approach correlated to the needs of already existing clients and potential clients (establishing a plan, conversation, news promotion, interaction, identifying new applications, new topics of interest, measuring the impact in a certain field). The IT driven society helps businesses communicate their message to the clients more clearly through its channels, motivate them, and make them be interested in their product faster, creating trust and meeting their needs through its products, making 
them loyal to a much greater extent. These management strategies that underlie customer understanding and anticipation are effectively supported by the digitalization process.

\section{CONCLUSIONS}

Today's managers need to demonstrate a capacity and power of understanding and anticipation of the new technologies they interact with, with an open attitude towards change, to give them the courage to capitalize on the knowledge for the development of their organizations. Even their ability to identify timely trends that can influence the activity in the environment It should not be neglected. Also, another valuable ability is to stimulate a work environment based on the knowledge of experts useful to the company, boosting it in an efficient way. The focus of current management on openness and innovation is the key to success, therefore the roles of team members must be clear, enabling the team to self-organize to achieve short-term goals. Transparency of rules makes it easier to achieve goals, and accessing trends emerging in the field of activity opens new ways of success.

Today, more than ever, IT is part of our everyday life but also part of the life of organizations - requiring managers to reformulate their managerial process and upgrade it to the digitized present. We all feel the need for change, transformation, reinvention, but few have the capacity to succeed, which requires, among many others, qualities such as: support, determination, passion, risk taking, courage, will, perseverance, confidence in human potential, adaptability, positive and innovative thinking, self-confidence, and, last but not least, a team according to the manager's vision.

The new technologies have had and have a positive impact on humanity as well as on the business environment in general, facilitating the access of more customers as possible to their products/services, but also stimulating creativity by getting things done not only better but cleverer and faster-increasing user comfort, anticipating specific needs related to that product/service. Another IT benefit is adapting the product to the specific needs of potential customers accessing the product through the Internet - quick feedback on products and the ability to meet needs that the organization did not know they had when creating the product. The enemy of an organization in the digital era of the business environment is unprecedented competition. In this situation, managerial abilities are put to the test, as organizational changes pose a challenge. We have shown above qualities that make the difference between a successful manager and a poor performer and it has come to light that confidence in this "hot" environment can make a difference. In addition, the manager must surround himself with competent employees with creative and professional capabilities tailored to continuously surpass the goals initially established.

\section{ACKNOWLEDGMENT}

This study was conducted through the doctoral and post-doctoral advanced research programs, Management field, coordinator The Bucharest University of Economic Studies. 


\section{REFERENCES}

Alkhafaji, A. (1995). Competitive Global Management - Principles and Strategies. USA: St. Lucie Press

Bhagat, R. S., Triandis, H. C., \& McDevitt, A. S. (2012). Managing Global Organizations: A Cultural Perspective. Cheltenham: Edward Elgar Publishing Limited

Burduș, E., \& Popa, I. (2013). Fundamentele managementului organizației. Bucharest: ProUniversitaria

Cortada, J. W. (2009). How Societies Embrace Information Technology: Lessons for Management and the Rest of Us. John Wiley \& Sons Inc.

Dolata, M., \& Standa, A. (2014). The specificity of manager in project management. In A. Stabryta, \& K. Woźniak, Managing Organizations in the Information Society (pp. 19-32). Krakow: Mfiles.pl

Feather, J. (2004). The Information Society: A Study of Continuity and Change (fourth edition). London: Facet Publishing

Hamel, G. B. (2007). The Future of Management. Boston: Harvard Business School Press

Hill, J. (2009). International Business: Managing Globalization. SAGE Publishing

Lane, H. W., Maznevski, M. L., Mendenhall, M. E., \& McNett, J. (2004). The Blackwell Handbook of Global Management: A Guide to Managing Complexity. Oxford: Blackwell Publishing

Moran, R. T., Harris, P. R., \& Moran, S. V. (2011). Managing Cultural Differences: Leadership Skills and Strategies for Working in a Global World (eighth edition). Oxford: Elsevier Inc.

Parker, B. (2005). Introduction to Globalization and Business: Relationships and Responsibilities. London: SAGE Publications

Rao, C. (2001). Globalization and Its Managerial Implications. Connecticut: Quorum Books.

Ribeiro, N. (2011). Managing in the Digital Era. Lisbon: lulu.com

Singh, P., \& Verma, S. (2010). Organizing and Managing in the Era of Globalization. London: Sage Publications Ltd.

Tansey, S. D., Darnton, G., \& Waterbridge, J. (2003). Business, Information Technology and Society. London: Routledge

Thomas, D. C. (2008). Cross-Cultural Management: Essential Concepts. London: SAGE Publications Ltd. 